\title{
Determination of relevance between surface free energy and adsorption capacity of cement particles
}

\author{
Jihai $\mathrm{Yu}^{1}$, Zhengmao $\mathrm{Ye}^{1}$, \\ Zhenzhen $\mathrm{Xia}^{1}$, Bin $\mathrm{Wu}^{1}$, \\ Pengkun $\mathrm{Hou}^{1}$
}

\footnotetext{
${ }^{1}$ Shandong Provincial Key Laboratory of Preparation and Measurement of Building Materials, University of Jinan, Jinan, Shandong Province, China e-mail: shenlan_990223@163.com; mse_yezm@ujn.edu.cn; xzz891603086@126.com; 983094698@qq.com; 122567517@qq.com
}

\begin{abstract}
The compatibility between superplasticizer and cement was influenced by the adsorption capacity of cement particles. This study investigated the relevance between the adsorption capability and surface free energy. Adsorption capacity and surface free energy of both sulphoaluminate cement and portland cement were measured. The adsorption capacity of cement particles was measured by ultraviolet spectrophotometry. The test showed that particles of sulphoaluminate cement adsorbed more molecules of superplasticizer than portland cement particles. The weight of superplasticizer adsorbed by $2 \mathrm{~g}$ of sulphoaluminate cement and portland cement were $0.28 \mathrm{mg}$ and $0.159 \mathrm{mg}$ respectively. Surface free energy of cement particles was calculated by contact angle and the contact angles were determined by the thin-layer wicking technique and washburn equation which is theoretical basis of thin-layer wiching technique presented by Chibowski E. The sulphoaluminate cement, portland cement's surface free energy were $51.46 \mathrm{~mJ} \cdot \mathrm{m}^{-2}$ and $49.36 \mathrm{~mJ} \cdot \mathrm{m}^{-2}$ respectively. The results showed that the higher adsorption capacity of particles was usual accompanied by higher surface free energy. The fluidity of cement paste was influenced by the adsorption capacity of cement particles because the more molecules of superplasticizer was adsorbed by cement particles there were lacking superplasticizer in the paste. The macro-behaviour of higher adsorption capacity is that the cement paste need more superplasticizer to reach the needed fluidity.
\end{abstract}

Key words: surface free energy, adsorption, fluidity.

\section{INTRODUCTION}

Cement materials are widely used currently. Sulphoaluminate cement is one of them, it is widely used in marine construction engineering due to excellent protection from chemical attacks and high early age strength. However, there is a severe problem that some cement materials are not compatible with amino and naphthalene-based superplasticizers in practical applications. WANG et al. [1] found that superplasticizers are generally surfactant, which can improve the physical stability of the cement-water disperse system. The key factor that affects the adjustability between cement and superplasticizer is the action mechanism of superplasticizer and the characteristics of cement particles. Now most of the superplasticizer work because of its dispersing ability. Meanwhile the dispersing ability of superplasticizers will be influenced by adsorption capacity of cement particles. QU et al. [2] have reported that the adsorption of cement particles can be influenced by many factors such as mineral composition of cement, alkali sulphate and mineral admixture in cement. MALHOTRA S K et al. [3] found that different grade of portland cement showed different compatibility with superplasticizer. It is not always necessary that the dose recommended by the manufacturer may always hold proper with the materials and their proportions used in a particular work. ERDOGDU S [4] found that the mineral compositon of cement will influenced the adsorbed capability of cement particles and the effect of a superplasticizing admixture depends on the composition of cement rather than the amount used. KRISHNA R N. et al.[5] reported that the dispersing action of the superplasticizer was maximum for lignite fly ash. Among the different grades of cements, the dispersing action is maximum for the cement containing the least amount of $\mathrm{C}_{3} \mathrm{~A}$. The adsorption of superplasticizer is reduced when cement is blended with fly ash. KIMA B G et al.[6] showed that the cement containing low amount of soluble alkali 
have a tendency to adsorb a high amount of superplasticizer, while the cements containing high amout of soluble alkali do not. CHIOCCHIO G et al.[7] and HSU K C et al.[8] found that The fluidity of portland cement pastes is greatly affected by the time of addition of the superplasticizers. When the addition of superplasticizer is delayed the workability is always found to be higher. However there are few reports about the relevance between adsorption capability and surface free energy of cement particles. It is necessary to research the relationship between adsorption capability and surface free energy for further study on the adjustability between cement and superplasticizers. In addition, the surface free energy of the cement also has been investigated $[9,10]$ because of its influence on the wettability of the components of cement materials and their surface interactions[11,12]. In this paper, adsorption capacity and surface free energy of cement particles were discussed. The fluidity of cement paste was measured to show influence of adsorption capacity on adjustability between cement and superplasticizers.

\section{MATERIALS AND METHODS}

\subsection{Materials}

Table 1: Chemical composition and physical properties of cement (wt \%).

\begin{tabular}{c|c|c|c|c|c|c|c|c}
\hline CEMENT & $\mathbf{S i O}_{2}$ & $\mathbf{F e}_{2} \mathrm{O}_{3}$ & $\mathbf{A l}_{2} \mathrm{O}_{3}$ & $\mathbf{C a O}$ & $\mathbf{M g O}$ & $\mathbf{S O}_{3}$ & $\begin{array}{c}\text { DENSITY } \\
\left(\mathbf{g} \cdot \mathbf{c m}^{-3} \mathbf{)}\right.\end{array}$ & $\begin{array}{c}\text { SPECIFIC SURFACE AREA } \\
\left(\mathbf{m}^{2} \cdot \mathbf{k g}^{-1} \mathbf{)}\right.\end{array}$ \\
\hline $\begin{array}{c}\text { Sulphoaluminate } \\
\text { cement }\end{array}$ & 10.96 & 3.71 & 28.9 & 45.25 & 1.45 & 8.88 & 2.90 & 367.0 \\
\hline portland cement & 19.95 & 2.90 & 4.71 & 60.58 & 1.41 & - & 3.08 & 360.0 \\
\hline
\end{tabular}

Sulphoaluminate cement and portland cement were produced by factories in Shandong Province. The chemical components and physical properties of the cement materials are listed in table 1. Propanetriol, 1-bromonaphthalene and deionized water were used as penetrating liquids to compared with n-heptane, respectively. The physical properties of the penetrating liquids are presented in table 2. Propanetriol was used as probe liquids in the determination of the surface free energy. All the reagent used in the test were analytical grade and commercially available.

Table 2: Viscosity, surface tension and surface free energy parameter of the penetrating liquids at 25.

\begin{tabular}{|c|c|c|c|c|c|}
\hline PENETRATING LIQUID & $\begin{array}{c}\text { VISCOSITY } \\
\text { (mPa.s) }\end{array}$ & $\begin{array}{l}\text { SURFACE } \\
\text { TENSION } \\
\left(\mathrm{mN} \cdot \mathrm{m}^{-1}\right)\end{array}$ & $\begin{array}{c}\text { DISPERSIVE } \\
\text { COMPONENT } \\
\text { OF SURFACE } \\
\text { FREE } \\
\text { ENERGY } \\
\mathrm{V}^{\mathrm{LW}} \\
\left(\mathrm{L} / \mathrm{mJ} \cdot \mathrm{m}^{-2}\right)\end{array}$ & $\begin{array}{c}\text { POLOR } \\
\text { ELECTRON } \\
\text { DONOR } \\
\text { COMPONENT } \\
\mathrm{y}^{+} \\
\left(\mathrm{L} / \mathrm{mJ}^{-} \mathrm{m}^{-2}\right)\end{array}$ & $\begin{array}{l}\text { POLOR ELECTRON } \\
\text { ACCEPTOR } \\
\text { COMPONENT } \\
\mathrm{Y}- \\
\left(\mathrm{L} / \mathrm{mJ} \cdot \mathrm{m}^{-2}\right)\end{array}$ \\
\hline N-heptane & 0.4169 & 20.1 & 20.1 & 0 & 0 \\
\hline Deionized water & 1.002 & 72.8 & 21.8 & 25.5 & 25.5 \\
\hline 1-bromonaphthalene & 4.690 & 44.4 & 44.4 & 0 & 0 \\
\hline Formamide & 3.116 & 58.0 & 39.0 & 2.28 & 39.6 \\
\hline
\end{tabular}




\subsection{Methods}

Naphthalene based superplasticizer was used as adsorbent. Before this test, naphthalene based superplasticizer solutions with different concentration were taken for ultraviolet spectrophotometry to find the characteristic absorption peak, as is shown in the figure 1. A curve of concentration to absorbance can be obtained by linear fitting method at the wavelength of $229 \mathrm{~nm}$, which was shown in figure 1 . In the test, $2 \mathrm{~g}$ of cement were put into $100 \mathrm{~g}$ deionized water to get the suspension of cement particles. Naphthalene based superplasticizer was added into the suspension as soon as the cement was put into the deionized water. A certain amount of suspension was taken out for centrifuging and the supernatant was taken for ultraviolet spectrophotometry as soon as superplasticizer was added in. Then the absorbance of the supernatant can be got. The weight of superplasticizer adsorbed by cement particles could be calculated refer to the standard adsorption curve of the naphthalene based superplasticizer as is shown in figure 2 .

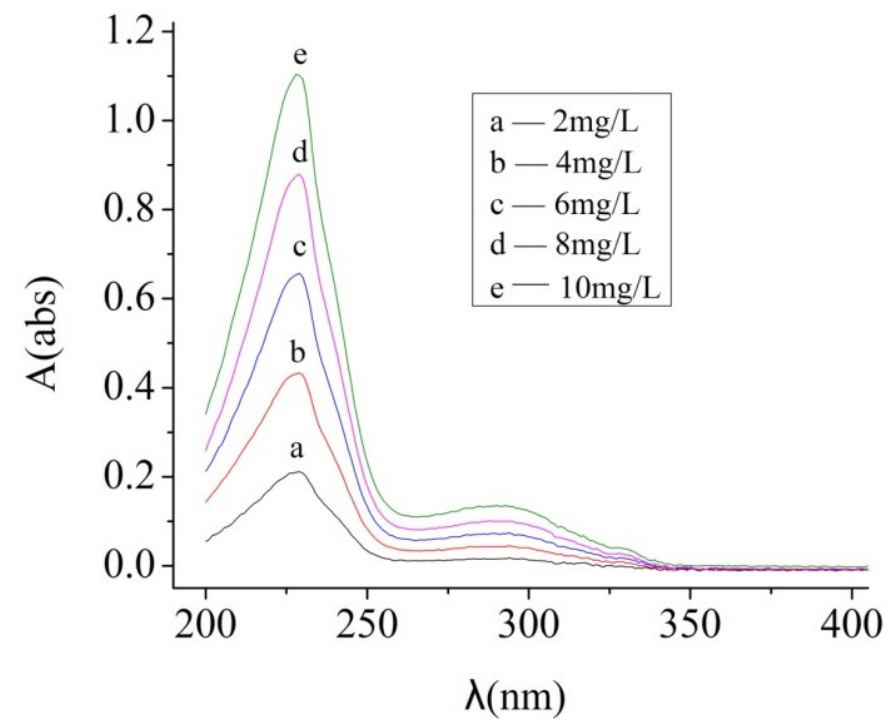

Figure 1: The adsorption spectra of standard solution of naphthalene-based superplasticizer.

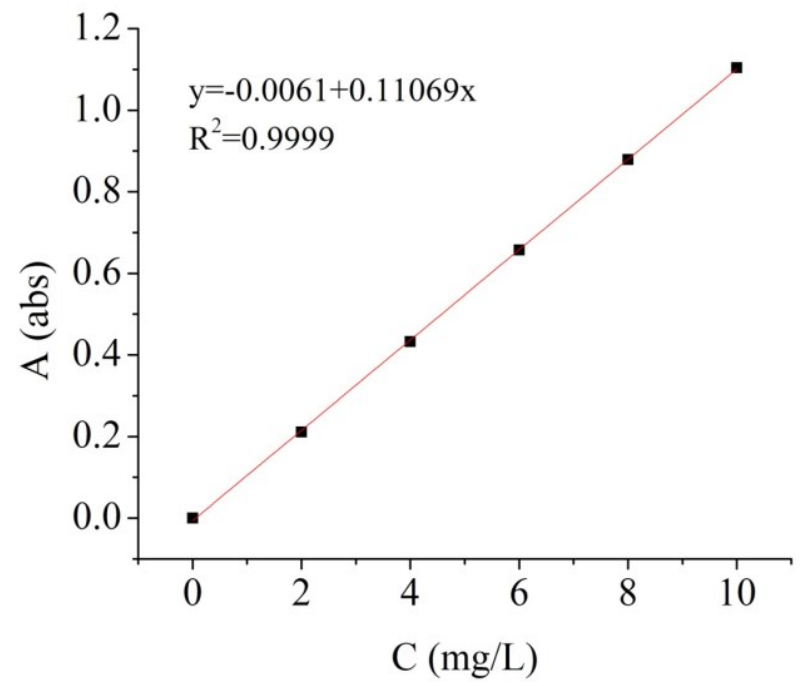

Figure 2: The standard adsorption curve of naphthalene based superplasticizer. 
The usual measurement of contact angle can't be used in this test, because the probing liquid used in the contact angle measurement has a low viscosity and can infiltrate into the thin layer of cement particles quickly. VAN OSS et al.[13] have calculated that the contact angle of the probe liquid on cement particles sample can be generally determined by the thin-layer wicking technique. The figure 3 is the diagram of experimental device. CHIBOWSKI E et al. [14] have calculated that the contact angle of powders can be obtained via Washburn equation(equation 1). The results were reported in table 4. The surface free energy which conclude $\gamma_{\mathrm{S}}{ }^{+}$(Polor electron donor component) and $\gamma_{\mathrm{S}}{ }^{-}$(Polor electron acceptor component) of a cement powder has been studied $[15,16]$ that it can then be calculated by the Lifshitz-van der Waals equation(equation 2-6) .

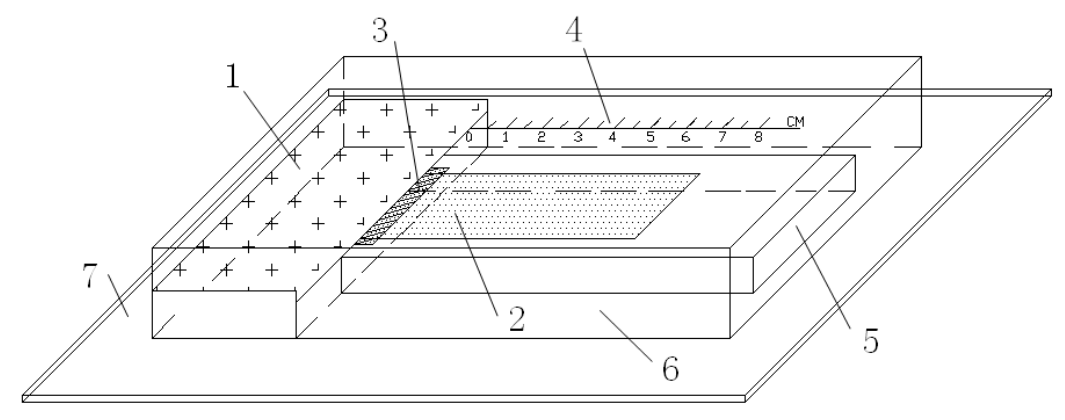

1-penetrating fluid and degreasing cotton, 2-glass slide covered by thin layer of cement particles, 3-medium speed

filter paper, 4-scale, 5-supporting, 6-out cover, 7-base plate

Figure 3: The diagram of experimental device of contact angle.

$$
\begin{aligned}
& X^{2}=\frac{t \cdot R_{e f f} \cdot \gamma \cdot \cos \theta}{2 \eta} \\
& \sqrt{\gamma_{L(a)}^{-}} \sqrt{\gamma_{S}^{+}}+\sqrt{\gamma_{L(a)}^{+}} \sqrt{\gamma_{S}^{-}}=\frac{1}{2}\left(\gamma_{L(a)}^{L W}+2 \sqrt{\gamma_{L(a)}^{+} \gamma_{L(a)}^{-}}\right)(1+\cos \theta)-\sqrt{\gamma_{S}^{L W} \gamma_{L(a)}^{L W}} \\
& \sqrt{\gamma_{L(b)}^{-}} \sqrt{\gamma_{S}^{+}}+\sqrt{\gamma_{L(b)}^{+}} \sqrt{\gamma_{S}^{-}}=\frac{1}{2}\left(\gamma_{L(b)}^{L W}+2 \sqrt{\gamma_{L(b)}^{+} \gamma_{L(b)}^{-}}\right)(1+\cos \theta)-\sqrt{\gamma_{S}^{L W} \gamma_{L(b)}^{L W}} \\
& \gamma_{S}^{L W}=\frac{\gamma_{L}^{L W}(1+\cos \theta)^{2}}{4} \\
& \gamma_{S}^{A B}=2 \sqrt{\gamma_{S}^{+} \gamma_{S}^{-}} \\
& \gamma_{S}=\gamma_{S}^{L W}+\gamma_{S}^{A B}
\end{aligned}
$$

The fluidity of cement paste was measured according to miniflow test. Deionized water and naphthalene based superplasticizer were added to a mixing container. Then cement was added and the mixture was stirred at low speed for $120 \mathrm{~s}$. Stop the mixer for $15 \mathrm{~s}$, during which any paste on the sides of the bowl is scraped down into the hatch. Then operate the mixer at high speed for $120 \mathrm{~s}$. After mixing, a portion of the mixtures was used for the mini-slump test. A flow cone specified in JIS R5201 was filled with the mixtures. After the cone was removed from the sample, the maximum diameter of the spread sample and the maximum width perpendicular to that diameter were measured. The average of these two values was defined as the fluidity. 


\section{RESULTS AND DISCUSSION}

\subsection{The adsorption capacity of sulphoaluminate cement and portland cement}

The experiment results of ultraviolet spectrophotometry listed in table 3 showed that the adsorption capacity of sulphoaluminate cement was higher. The concentration of superplasticizer in the suspension can be calculated by the standard absorption spectrum of naphthalene based superplasticizer then the adsorbance of superplasticizer by cement particles can be calculated. The weight of superplasticizer adsorbed by sulphoaluminate cement and portland cement were $0.28 \mathrm{~g}$ and $0.159 \mathrm{~g}$ respectively. The result was correspond to the laboratory finding of LIU et al.[17] They found that the adsorbing capacity of sulphoaluminate cement is 1.2-2.5 times of the adsorbing capacity of portland cement.

Table 3: The absorbance of the supernatant and the weight of superplasticizer adsorbed by cement particles.

\begin{tabular}{c|c|c}
\hline \multirow{2}{*}{ SAMPLE } & $\begin{array}{c}\text { THE ABSORBANCE OF } \\
\text { SUPERNATANT (abs) }\end{array}$ & $\begin{array}{c}\text { WEIGHT OF SUPERPLASTICIZER } \\
\text { ADSORBED BY CEMENT PARTICLES } \\
(\mathbf{m g})\end{array}$ \\
\hline Sulphoaluminate cement & 0.348 & 0.282 \\
\hline Portland cement & 0.482 & 0.159 \\
\hline
\end{tabular}

\subsection{The surface free energy of sulphoaluminate cement and portland cement particles}

Wicking technique was suitable to measure the contact angle. The curves as is shown in figure4 and figure 5 could be got by averaging the testing values of repeated measurements.

The thin-layer wicking measurement results are depicted in Figure 4 and Figure 6 . The curves were fitted via the origin point to get the slope values and contact angles were calculated by Washburn equation(equation 1) which is presented by CHIBOWSKI E et al. [14]. The data are listed in table 4. The contact angle of deionized water on the cement powder we have measured was close to the experimental result of LIU et al. [9] Substituting the contact angle of 1-bromonaphthalene in table 4 into the Lifshitz-vander Waals equation (equation 2-6), one can calculate the surface free energy of the samples.

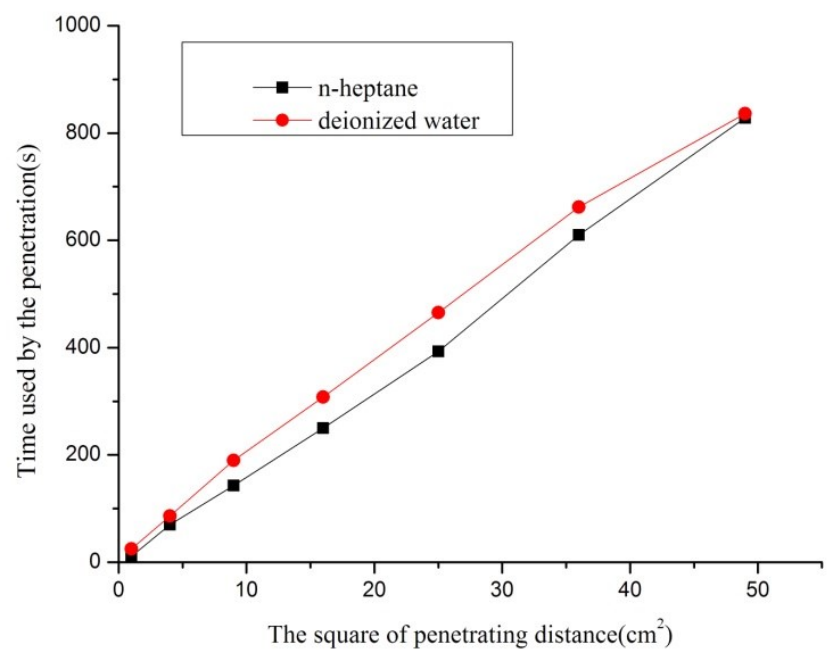

Figure 4: Square of distance of deionized water and n-heptane moved through the thin plate of sulphoaluminate cement particles against time used. 


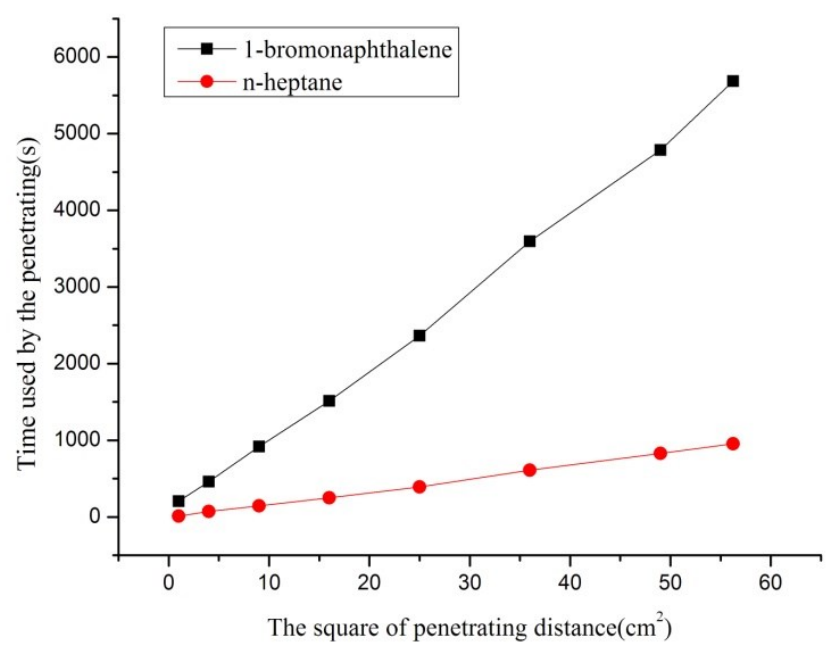

Figure 5: Square of distance of n-heptane and 1-bromonaphthalene moved through the thin plate of sulphoaluminate cement particles against time used.

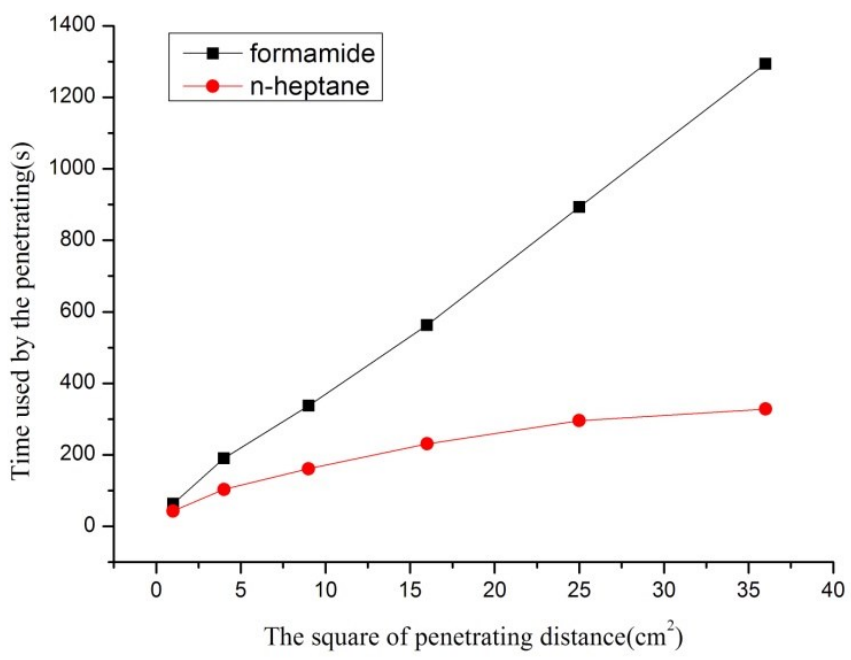

Figure 6: Square of distance of $n$-heptane and formamide moved through the thin plate of sulphoaluminate cement particles against time used. 
Table 4: $\mathrm{K}$ values and the contact angles of the penetrating liquids at the surface of sulphoaluminate cement.

\begin{tabular}{c|c|c}
\hline FLUID & $\begin{array}{c}\text { SLOPEOF PERMEATION } \\
\text { CURVES K }\end{array}$ & CONTACT ANGLE $^{\circ}$ \\
\hline N-heptane & 17.08 & 0 \\
\hline Deionized water & 16.99 & 51.84 \\
\hline 1-bromonaphthalene & 98.62 & 24.13 \\
\hline Formamide & 34.77 & 43.5 \\
\hline
\end{tabular}

The surface free energy, $\gamma_{\mathrm{s}}$ of the cement samples can then obtained. The method to calculate the surface free energy of portland cement particles is the same with sulphoaluminate cement particles, so the procedure was abbreviatory. The final results are presented in table 5.

Table 5: Surface free energy of test samples.

\begin{tabular}{c|c}
\hline SAMPLE & $\begin{array}{c}\text { SURFACE FREE ENERGY } \mathbf{s} \\
/ \mathrm{mJ}^{-2}\end{array}$ \\
\hline Sulphoaluminate cement & 51.51 \\
\hline Portland cement & 49.36 \\
\hline
\end{tabular}

The datas in table 5 shows that the surface free energies of two kinds of cement were $51.51 \mathrm{~mJ} \cdot \mathrm{m}^{-2}$ and $49.36 \mathrm{~mJ} \cdot \mathrm{m}^{-2}$, it can be seen from Table 5 that the surface free energy of the sulfoaluminate cement particles is higher.

The adsorption capacity and surface free energy of cement particles have hydrated for 6 hours were also measured for further study on the relevance between adsorption capacity and surface free energy. The weight of superplasticizer adsorbed by cement particles increased to $0.46 \mathrm{mg}$ and $0.311 \mathrm{mg}$. The surface free energy of two kinds of cement partcles were $58.25 \mathrm{~mJ} \cdot \mathrm{m}^{-2}$ and $56.32 \mathrm{~mJ} \cdot \mathrm{m}^{-2}$ respectively. In other words, higher surface free energy represents higher adsorption capability of cement partecles.

\subsection{The cement paste fluidity of sulphoaluminate cement and portland cement}

The fluidity of both portland cement and sulphaluminate cement paste were measured by miniflow test. The result was shown in table 6 .

Table 6: The fluidity of portland cement and sulphoaluminate cement paste (mm).

\begin{tabular}{c|c|c|c|c|c|c}
\hline & \multicolumn{3}{|c|}{ PORTLAND CEMENT } & \multicolumn{3}{|c}{ SULPHOALUMINATE CEMENT } \\
\hline Content of superplasticizer (\%) & 0.5 & 0.7 & 1.0 & 1.3 & 1.5 & 1.7 \\
\hline Initial fluidity (mm) & 175 & 235 & 255 & 185 & 235 & 252 \\
\hline Fluidity after 30 minutes (mm) & - & 160 & 190 & - & - & 145 \\
\hline
\end{tabular}

It can be found that the dosage of superplasticizer in sulphoaluminate cement was larger to reach ideal fluidity than portland cement. The loss of fluidity of sulphoaluminate cement was also larger than that of portland cement. ZHANG et al.[18] have found out that there are more superplasticizer molecules adsorbed on the surface of sulphoaluminate cement particles and they will be covered by hydration products during the hydration of cement the superplasticizer adsorbed. Then superplasticizer would be consumed quickly and the cement particles in the liquid phase would be agglomerated due to the lack of superplasticizer which functionalized as a dispersant. In the meantime, the agglomeration of the cement particles increases enclosed 
water, the following hydration of the internal part of cement particles would be influenced and the performance of the cement materials would be worse. The above measurement results suggest that the sulphoaluminate cement need much more superplasticizer to achieve expected effect. The data in the table 6 also showed that the fluidity loss ratio of sulphoaluminate cement paste is higher than that of portland cement paste because the hydration of sulphoaluminate cement is faster than portland cement, more molecules of superplasticizer were covered by hydration products of sulphoaluminate cement particles.

\section{CONCLUSION}

The adsorption capacity of sulphoaluminate cement particles were stronger and it increased during the hydration of the cement. The weight of superplasticizer adsorbed by cement particles are $0.28 \mathrm{mg}$ and 0.159 $\mathrm{mg}$ respectively, the weight of superplasticizer adsorbed increased to $0.46 \mathrm{mg}$ and $0.311 \mathrm{mg}$ when the cement particles have hydrated for 6 hours.

The surface free energy of two kinds of cement partcles were $51.51 \mathrm{~mJ} \cdot \mathrm{m}^{-2}$ and $49.36 \mathrm{~mJ} \cdot \mathrm{m}^{-2}$ respectively, which were $58.25 \mathrm{~mJ} \cdot \mathrm{m}^{-2}$ and $56.32 \mathrm{~mJ} \cdot \mathrm{m}^{-2}$ when the cement particles had been hydrated for 6 hours. This shows the same tendency with adsorption capacity. The adsorption capacity of cement particles can also be reflected by cement paste fluidity. The stronger adsorption capacity of cement particles the poorer fluidity of cement paste.

The results of investigation show that the adsorption capacity of cement particles increases with higher surface free energy. This approach provides a new way to reflect the adsorption capacity of cement particles and has great potential for improving the compatibility between cement and superplasticizers. Therefore, many further works remain to be done to definite the relevance between adsorption capacity and surface free energy of cement particles.

\section{ACKNOWLEDGMENTS}

This work is supported by National Natural Science Foundation of China (No. 51272092, No.51302105). Meanwhile, this work is supported by Program for Scientific Research Innovation Team in Colleges and Universities of Shandong Province.

\section{BIBLIOGRAPHY}

[1] WANG, H. "Compatibility of Concrete Water reducers With Cement", J. Shandong Building Materials n.1, pp. 8-10, Sept. 2005.

[2] QU, J.D., PENG, J.H., CHEN, M.F., et al., "The research progress of adsorption properties of water reducers on the cement particles" Journal of Building Materials, v.8 n.4, pp. 410-417, Aug. 2005.

[3] MALHOTRA, S. K, MASOOD, I., MALHOTRA, S. K., "Compatibility of superplasticizers with different cements" Construction and Building Materials, v.14 n.5, pp. 253 -257, July 2000.

[4] ERDOGDU, S. "Compatibility of superplasticizers with cements different in composition", Cement and Concrete Research, v.30 n.5, pp. 767 -773. May.2000.

[5] KRISHNA R N. "Dispersing action of a superplasticizer with different grades of cements and fly ash" ACI Materials Journal, v.93n.4, pp. 351 -355. 1996.

[6] KIMA, B.G, JIANG, S.P, JOLICOEUR, C. "The adsorption behavior of PNS superplasticizer and its relation to fluidity of cement paste", Cement and Concrete Research, v.30 n.6, pp. 887 -893, June 2000.

[7] CHIOCCHIO G, PAOLINI A E. "Optimum time for adding superplasticizers to Portland cement pastes", Cement and Concrete Research, v.15 n.5, pp. 901 -908, Sept.1985.

[8] HSU, K. C, CHIU, J. J. "Effect of addition time of a superplasticizer on cement adsorption and on concrete workability", Cement and Concrete Composites, v.21 n.5, pp. 425 -430. Dec. 1999.

[9] LIU, J.P., LI, H., TIAN, Q., WANG, Y. J., "Determination of dynamic contact angles of cement and mineral admixtures based on thin-layer wicking technique". Journal Of Southeast University(Natural Science Edition), v.43 n.5, pp,1074-1079, Sept. 2013.

[10] ZHU, Y.J., Effect Mechanism Research of Water Reducer on Dry Shrinkage of Cement Concrete, Tese de M.Sc. China Building Materials Academy, Bei Jing, China, 2006.

[11] ASAMOTO, S., ISHIDA, T., "Microscopic approach to time-dependent deformation mechanism of concrete based on liquid characteristics", Journal of Materials, Concrete Structures, Pavements, JSCE, pp, 159-172, 2004 
[12] SUN, Z. W., Influence of surface energy on fracture energy and strength of cement based materials, Qing Dao, Qing dao Technological University, 2008.

[13] COSTANZO, P.M., GIESE, R.F., VAN OSS, C.J., "The determination of surface tension parameters of powders by thin layer wicking" Advances in Measurement and Control of Colloidal Processes, pp, 223-232, 1991

[14] CHIBOWSKI, E., GONZALEZ-CABALlERO, F., "Theory and practice of thin-layer wicking". Langmuir, v9 n1. pp. 330-340, Sept. 1993.

[15] VAN OSS, C.J., GOOD, R.J., CHAUNDURY, M.K., "The role of van der Waals force and hydrogen bonds in hydrophobic interaction" between biopolymer and low energy surfaces" Journal of Colloid Interface Science, v.111 n.2. pp. 378-390, June, 1986.

[16] FOWKES, FREDERICK, M., "Role of acid-base interfacial bonding in adhesion" Journal of Adhesion Science and Technology, v.1 n.1.pp. 7-27, 1987.

[17] LIU, T., LI, Y.J., CHEN, J., et al., "The research of adsorption of naphthalene-based superplasticizer on alite-sulphoaluminate cement”, Concrete, v.20 n.4. pp.73-76, 2013.

[18] ZHANG, M., ZHANG, D.C., WU, B., et al., "Compatibility of Water reducers With Sulphoaluminate Cement”, Journal Of Jinan University (Sci. \&Tech), v.20, n.2, pp. 125-129, Apr.2006. 